\section{THE SPECTRUM OF IRON AND THE PERIODIC LAW.}

I $\mathrm{N}$ the course of a prolonged series of spectroscopic observations on iron containing $\frac{1}{10}$ carbon, '08 sulphur, '070 phosphorus, and about ${ }^{4} \frac{4}{6}$ per cent. of manganese, and based on the previous investigations of Mr. Lockyer on the iron spectrum at varying temperatures, I noted some results summarized as follows :-

(1) Iron heated in vacuo evolves a vapour showing the $\mathrm{H}$ spectrum; in addition, other lines are sometimes visible.

(2) I have found that iron kept in a vacuum slowly evolves $\mathrm{H}$ at a temperature not exceeding $70^{\circ}-80^{\circ}$; this continued for six months. Further, on applying heat, I have observed a condensed sublimate at the sealed cold end of the tube.

Heated iron known to contain small quantities of some of the more fusible metals evolves these bodies, and vice vers $\hat{a}$ absorbs them. Exhausted heated iron also absorbs $\mathrm{H}$ in the same way, and most rapidly at an intense heat approximating to fusion.

(3) On iron being heated in the blow-pipe flame through which the spark was passing, lines were detected in the flame apart from the iron.

(4) On heating iron electrodes, "varying the tension of the spark, also the flame temperature," according to methods elsewhere given, I found it possible to obtain iron spectra, varying roughly in accordance with the heat of the flame and spark tension. Three nearly distinct spectra have been observed:-(I) Lowest heat, a nearly pure manganese spectrum. (2) Higher heat, manganese lines; other long lines appear, also the beginnings of a short-line spectrum. (3) Highest heat, a complete iron spectrum.

As regards the first spectrum, manganese has been identified by the ordinary method of chemical analysis. The second group of long lines the chemist would say were due to the presence of some body not identical with either iron or manganese, but this problematic body has not been identified or isolated; the proof is wanting, although it is a product, or function, of temperature, just as is the first or manganese spectrum. This spectrum may be due to dissociation of iron, and not to the vaporization of a foreign constituent. It is probable that iron can be roughly split up into two bodies, one of which is more volatile than the other, and that the relative quantity of each present may not always be the same. At any rate, it appears that by the simple heating of crude iron its composition may be sensibly modified, and that, even at a temperature as low as $70^{\circ}-80^{\circ}$, slow dissociation is going on, manifested by the evolution of hydrogen; and this continues, the rate of dissociation apparently broadly corresponding to the heat applied. It follows that in actual practice the chemical composition of iron may thus be altered, such changes being probably so minute as to escape recognition.

These researches were made with the sole object of utilizing the spectroscope as an aid to the ordinary chemical analysis of iron, my previous experience having taught me that an extension of the usual methods was imperatively required. It was thought that by the spectroscopic method some body or bodies as yet unrecognized might be found; in other words, I searched for so-called impurities with but scant success.

Finally, I was forced to admit that I had exhausted the purely analytical part of the inquiry, and must seek for the solution of the many discrepancies observed in the behaviour of iron and steel, and not comparable with its chemical composition as determined by ordinary analysis Nothing was left for further study, with the exception of the metal itself. It may be remarked, however, that

$$
\text { x Suggested by Mr. Lockyer. }
$$

NO. I I 59, VOL. 45] absolutely pure metal could not be obtained; manganese, for instance, seems always present, even after repeated purifications.

This led to a study of the periodic law as enunciated by Mr. Crookes in his address on the genesis of the elements. He advances the rational hypothesis that atoms are formed from the original protyle or fire mist ; next, by a series of atomic condensations, due to successive coolings, the elements are formed. Mr. Lockyer, by somewhat different methods of research, appears to have come to the same conclusion-viz. that temperature governs all ; and tells us, "as the result of a long series of spectroscopic observations," that an element is a very complex thing, broken up-at higher temperatures-into simpler things.

Mr. Crookes, by a careful study of the periodic law, supplemented by spectroscopic work, shows how elements may be built up. Mr. Lockyer, pursuing the opposite method, viz. by a study of the breaking up of the so-called elements, and registering the results by means of the spectroscope, appears to have experimentally proved the same thing.

It is quite obvious that an absolutely pure element can only exist at a given temperature ; any deviation from this - the critical temperature-must favour partial dissociation, and in this way it undergoes changes which may veil its true atomic weight. As Mr. Crookes puts it, "of a given mass of atoms, only a few may have the true atomic weight, the others slightly varying from it." Granting a variation of atomic weight in the element for the same reason, there may be a shifting of its spectral lines. I submit also that the discrepancies in the position of certain spectral lines may be due to divergence from the critical temperature, and not observational errors. ${ }^{1}$

There appears, therefore, to be no necessity for the use of such phrases as chemical affinity, cohesive force, \&c. : heat energy and the universal law of gravitation seem the only factors controlling the genesis of the elements-can we also say the genesis of known chemical compounds?

We cannot well say how far the physical properties of such a metal as iron are modified by temperature variations; yet we have seen that something like dissociation is going on at $70^{\circ}-80^{\circ}$, and that at a moderate heat this is accentuated; whilst at high temperatures the spectrum of iron affords ample proof that such is the case. Experiments have been made showing that even at the bare fusion-point of iron matter is volatilized; and at the abnormally high temperature of the Bessemer blow" melting up lumps of cold steel plunged in, and weighing 2 or more cwt, like wax"-it is admitted that iron as such is vaporized. It seems therefore, on the whole, that even a stable body like iron, when heated, gives results according with the periodic law; and as regards other bodies, from ice upwards, we do not need to be informed that evaporation (dissociation) is constantly going on.

It may not, however, be so well known that "on heating some of the more fusible metals in a vacuum," it is possible to obtain almost invisible vapours, some of which iron occludes or absorbs just as it does the gases hydrogen and possibly carbon monoxide.

Referring to the No. 2 spectrum indicating the probable existence of an intermediate body betwixt iron and manganese, not yet isolated, but which, nevertheless, is a product or function of the temperature, just as manganese is; the supposition that this body is a constituent of iron acquires force from the fact that recently it has been shown that iron may be capable of assuming two formsthe one termed $a$, or soft iron; the other $\beta$, or hard iron.

I Or, possibly, at a given temperature a vapour may be evolved from one body so nearly approximating in composition to that of another, the latter not necessarily at the same temperature, as to be almost undistinguishable from the other by the ordinary method of micrometric measurement. The same difficulty in another form occurs in ordinary chemical work: bodies are so closely allied in some instances as to render their separation and identification very difficult. 
Consequently, the physical properties of the metal are modified in accordance with the relative proportions of each present.

It is thought that pure iron may contain both $\alpha$ and $\beta$ iron ; but it is certain that when alloyed with other bodies -more especially carbon-these allotropic changes of iron become very marked. In this connection the author noted long ago that the carbon-iron alloys were more liable to change, and more sensitive to variations of temperature, than iron alloyed with other bodies; and, as the results of experience given, he goes so far as to advocate the substitution of other than carbon-iron alloy, in the following words:-

"For the production of steel in large masses suitable for ship and boiler plates, rails, \&c., the traditional rules of the old school of steel-casters cannot well be applied.

"What is desired is a strong ductile material, capable of resisting sudden shock or impact, and sudden or extreme changes in temperature-a material as insensible as may be to all influence except that due to fair wear. This material-i.e. low carbon, Bessemer, or Siemens steel-has almost superseded wrought-iron, and yet is not always to be relied upon. Under certain ill-understood conditions this metal sometimes behaves in a manner which has not been satisfactorily explained.

"Must we infer that carbon may be the culprit, and that the carbon-iron alloy is more sensitive to external influences, and more liable to molecular changes, than other iron alloys free from carbon ? 1

"It is quite possible that further study and experiment may result in the production of an iron alloy, capable alike of being forged or cast in amorphous masses free from any tendency to hardness or temper."

Osmond's researches have deservedly attracted great attention, and, in conjunction with the work of Prof. Ball and Prof Roberts-Austen, have on the whole been approved and accepted by men of science.

With the aid of the Le Chatelier's pyrometer, the critical points of temperature, i.e. the points at which molecular changes take place, have been determined. The whole series of these masterly researches cannot here be given in detail ; but after careful consideration the writer thinks they go far to prove that the undoubted molecular changes which take place when iron is heated simply represent marked periods of dissociation. That, broadly speaking, the results are in accord with the periodic law; with the spectroscopic work of Mr. Lockyer, and the researches of Mr. Crookes, together with the author's research on the behaviour of iron at varying temperatures; to say nothing of the work of other chemists all pointing in the same direction. As before said, the physical properties of iron are a function of temperature ; indeed, one is fain to say that the absolute elementary body can only exist as such at a given temperature; at any other, it cannot, strictly speaking, be that body.

Appreciable dissociation can, however, only be noted at comparatively wide intervals of temperature; minor changes must, of course, be beyond recognition to our senses. It is possible that the first beginning, so to speak, of dissociation may be detected with the spectroscope ; but unless carefully worked, the first spectroscopic indications of dissociation are not altogether trustworthy. The temperature of the spark and also the arc is subject to irregularities not easıly controlled; and unless worked by the experienced spectroscopist, the results are apt to be unsatisfactory.

It is remarkable that many eminent chemists reject the spectroscope as a means of research, and prefer other methods. Others, again, consider that these methods of

I Practically, we know that it is so; only pure carbon-iron alloys can be tempered and hardened with facility, the presence of other bodies tending to neutralize this effect; or, more plainly, the steel-smith terms it bad steel, which cannot be tempered or hardened properly.

NO. I I 59, vOL. 45] procedure fail to differentiate minute differences, which yet substantially exist. The method of spectrum analysis, however, seems capable of registering reactions beyond the scope of ordinary analysis. In fact, the instrument may be said to afford the same aid to the analyst in enabling him to note infinitesimal chemical changes or reactions, as the microscope affords for the discrimination and classification of microscopic objects.

On the whole, the results of a long series of patient investigations show that pure iron is probably a very complex body (as regards the commercial metal the microscopic researches of Sorby go to prove that it clearly is not, as usually assumed, a homogeneous body, but rather a heterogeneous one), extremely sensitive to external influences modified by the presence of minute proportions of other bodies; these latter, according to Prof. RobertsAusten, governing its physical properties in accordance with their atomic volume as compared with that of iron, and in accord with the periodic law. It is evident that it is not enough to give merely the simple percentage of carbon, sulphur, \&c., in iron ; the relative mass (as compared with iron) of the foreign ingredient must also be noted, and thus only can the absolute percentage composition be determined. Practical results appear to confirm those attained in theory.

The writer, when all these researches were not even thought of, in some notes on the working of steel, gathered from his own practice and confirmed by that of others, considered that the heat at which the steel was manipulated played a very important part, for the following reasons :-

Many discrepancies have been noted in the behaviour of steel-the results of the tests applied not at all corresponding to what might have been expected from its chemical composition. For instance, steel containing traces of silicon, 'I7 per cent. carbon, 06 of sulphur, '07 phosphorus, 40 per cent. manganese, stood a tensile strain of 27 to 30 tons per square inch; other samples of the same composition showed an increase of $3 \mathrm{I}$ to 35 per square inch, and under these latter conditions the carbon had to be reduced 12 per cent. to stand the normal test of 27 to 30 tensile strength.

The cause of this sudden change was not satisfactorily explained. I think a plausible explanation of these differences, which are of constant occurrence, may be traced to differences in temperature, and, strictly speaking, a steel of given chemical composition must be worked at a corresponding temperature to insure good results. Some clue to the temperature required nay, however, be obtained. The fusion point of steel varies with the amount of other matter alloyed with the pure ilon. All concerned in the manipulation of steel are well aware that hot or cold rolling makes a great difference in quality, and that the critical welding-point of the metal is confined to a narrow limit of heat; it is often a matter of great practical difficulty to decide upon the most suitable temperature necessary for good work. It is well known that steel may be seriously damaged either by under or over heating. In the first instance the steel may be too hard to bear rolling, or even if passed through it may not be sufficiently plastic to yield readily to pressure. We may in this case assume that minute cracks or flaws occur which cause a corresponding deterioration in strength. On the other hand, it is well known that if steel be over-heated it falls to pieces on further manipulation. The reason is apparent--it is approaching to a semi-fluid condition, and therefore cannot be rolled out. It may be, therefore, that for the successful working of steel it is not enough to rely simply on chemical analysis.

The foregoing seems to indicate that steel must be worked at a certain fixed, but as yet unknown, temperature below its fusion-point; at which heat the flow of 
heated metal undergoing compression and elongation is such as to insure good practical results.

It also follows that if the heat between these points can be ascertained, it may only be necessary to ascertain the fusion-point of any given steel, from which the working temperature can be determined, for the welding heat will obviously be a constant of temperature below the fusion-point of the steel sample, and it is probable that the discrepancies so often observable are simply due to deviations from the critical temperature required for welding and rolling purposes.

The welding or rolling heat should correspond to the fusion-point of steel, which is governed mainly by the amount of carbon it may contain, and possibly other elements may play a part in affecting the final result.

Finally, as the results of purely practical experience, the writer has been led to think that the term impurity, as applied to the mixed foreign elements present in iron, "is simply a conventional one, applicable only under certain rigid conditions of temperature combined with manipulation"; and these must be present in fixed quantities, bearing uniformly the same ratio to each other. It follows that under other conditions of temperature and manipulation a product possessing the same physical properties might be produced from a material sensibly differing in composition from that quoted above.

It is well known that those solely engaged in the manufacture of iron and steel have, "independent of the teachings of science," long ago come to the conclusion that iron undergoes unaccountable changes. It is asserted that ordinary chemical analyses afford no explanation of the observed phenomena; further research is insisted upon. To use their own words, they ask "What is iron? In our practice sornething often happens to iron of which your analyses afford no explanation." It is to be hoped that recent research has partly solved the problem; and that, by a further study of the metal itself, some clue may be found indicating more clearly than at present that iron is either a true chemical compound, or, if not, subject to allotropic modifications.

Practically, it does not seem to matter which, as, to quote the words of Dr. Gore, "every substance becomes a more or less cifferent substance at every different temperature" (Phil. Mag., May I 890).

\section{JOHN PARRY.}

\section{THE GROWTH OF THE PILCHARD OR SARDINE:}

I T was long since proved that the pilchard of the southwest coasts of England and the south coast of Ireland is the same species of fish as the sardine of the Atlantic coasts of France and Portugal, and of the Mediterranean. But there are apparent differences in the sizes and habits of these fish in different regions, of which the explanation has only recently been sought. The life-history of the species has been studied during the past few years with great care by several naturalists at various points of the coasts along which its habitat extends; and as a result of these researches, the extent to which its local peculiarities are real or only apparent is gradually being ascertained. Thus Marion at Marseilles has established the facts that the Mediterranean sardine in that neighbourhood spawns chiefly in February and March, but that the spawning period extends from December to May, that the adult fish does not exceed I $8 \mathrm{~cm}$. in length, and that the smallest sexually mature individuals are $15 \mathrm{~cm}$. long. The majority of the pilchards caught by drift-nets on the south coasts of Devon and Cornwall are from 20 to $25 \mathrm{~cm}$. in length, while those which I have seen in the ripe condition were 23 to $25 \mathrm{~cm}$. Thus it is clear that the Mediterranean sardine, at any rate in the Gulf of Lions, is in its adult state a much smaller fish than the Cornish pilchard, although no structural differences have yet been described which would separate the two as local races or varieties.

The well-known French sardine, such as we see it preserved in oil in tins, is also a small fish. The sardine fishery and the sardine-preserving industry in France are carried on along the south coast of Brittany from La Rochelle to Brest. The great majority of the sardines caught there are fish from 13 to $16 \mathrm{~cm}$. in length. Considering the short distance between Cornwall and Brittany, it might be suspected that these fish are not full grown; and Prof. Pouchet, Director of the Zoological Laboratory at Concarneau, tells us in his Reports that these sardines are young fish which have not yet reached sexual maturity. In fact, full-grown sardines of the same size as typical Cornish pilchards are also caught on the Breton coast, and are locally distinguished as "sardines de dérive," the small fish used for tinning being called "sardines de rogue." The adult sardines are captured principally in winter, the sardines de rogue in summer. The question therefore arises whether small pilchards of the same size as the sardines de roguc of the French coast occur on the coasts of Cornwall, and if not, why not. During the four years I have been at the Plymouth Laboratory I have never heard of any such fish being caught by the fishermen. Not long ago I asked $\mathrm{Mr}$. Dunn, who has been engaged in the Cornish pilchard trade the greater part of his life, if he had ever seen any pilchards of the same size as French sardines, and he said he never had. He is connected with the factory at Mevagissey, where adult pilchards are prepared in oil in tins in the same way as French sardines, and he told me that some years ago the owners of the factory took steps to ascertain whether pilchards of small size could be captured near Mevagissey. A seine of the kind used by the French fishermen was procured from France, and several trials were made with it ; but instead of half-grown pilchards of the required size, it captured only very young specimens 2 or 3 inches long. The recent capture, therefore, in nets belonging to the Marine Biological Association, of young pilchards similar in size to the French sariines de rogue is a matter of some interest and importance. The discovery also adds considerably to our knowledge of the growth and history of the pilchard.

Some months ago the Director of the Plymouth Laboratory was instructed to procure a fleet of smallmeshed drift-nets for the purpose of catching anchovies, in order to ascertain at what seasons and positions and in what abundance these fish appeared off Plymouth. These nets are five in number, each being 60 fathoms in length; the mesh is about $\frac{1}{2}$ inch square, or 70 meshes to the yard. They were shot a few miles outside Plymouth Breakwater on November $3,4,5$, and 6 , and on each occasion the chief part of the catch consisted of pilchards measuring I 3 to $16.5 \mathrm{~cm}$. in length. The rest of the catch consisted of a few full-grown pilchards. a few young nrackerel, a few sprats, and sometimes a few anchovies. On each occasion there was a considerable difference in size between the smallest of the large pilchards and the largest of the small. The spawning period of the pilchard off Plymouth extends from the beginning of June to the beginning of November-five months - and may possibly be prolonged a little beyond these limits. Now all the available evidence tends to show that even the smallest of the young pilchards above mentioned, $13 \mathrm{~cm}$. in length, could not have reached that size if hatched the same year, even if they were derived from eggs shed in May. For in the latter case they would be only a little more than five months old. Meyer found that herrings at five months were only 6 to $7 \mathrm{~cm}$. long, and Marion states that the sardine at Marseilles is $7 \mathrm{~cm}$. long at the same age. It might be argued that the Atlantic pilchard grows faster than the Mediterranean sardine, but it can scarcely grow so much faster as to reach $13 \mathrm{~cm}$. in five months. It is pretty

No. I I 59, voL. 45] 